\title{
Editorial
}

\section{Separation Methods in Biomedical Analysis, a Booming Field}

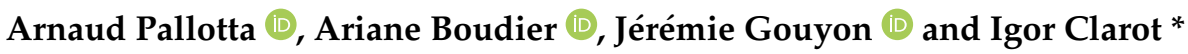 \\ Université de Lorraine, CITHEFOR, F-54000 Nancy, France; arnaud.pallotta@univ-lorraine.fr (A.P.); \\ ariane.boudier@univ-lorraine.fr (A.B.); jeremie.gouyon@univ-lorraine.fr (J.G.) \\ * Correspondence: igor.clarot@univ-lorraine.fr
}

check for

updates

Citation: Pallotta, A.; Boudier, A.; Gouyon, J.; Clarot, I. Separation

Methods in Biomedical Analysis, a Booming Field. Separations 2022, 9, 51. https://doi.org/10.3390/separations 9020051

Received: 7 February 2022

Accepted: 10 February 2022

Published: 11 February 2022

Publisher's Note: MDPI stays neutral with regard to jurisdictional claims in published maps and institutional affiliations.

Copyright: () 2022 by the authors. Licensee MDPI, Basel, Switzerland. This article is an open access article distributed under the terms and conditions of the Creative Commons Attribution (CC BY) license (https:// creativecommons.org/licenses/by/ $4.0 /)$.
Many scientific endeavors are dependent upon the accurate quantification of drugs and endogenous substances, such as pharmacokinetics [1], toxicokinetics [2], and exposureresponse (pharmacokinetics/pharmacodynamics) [3]. Bioequivalence [4], for example, is a surrogate end-point used by drug companies and regulatory agencies to determine the safety/suitability of new drug formulations for approval. The use of bioequivalence can replace the need for costly and lengthy large-scale patient trials. The accurate and reproducible measurement of drug concentrations (in current or in new formulations) is a regulatory requirement for approval of pharmaceutical products [5]. Although one may underestimate the development of adequate separative methods, its importance for pharmacy, medicine, and chemistry in general is a key point. Due to the stringent requirements in terms of method reliability, sensitivity, analysis speed, and sample throughput, the development of bioanalytical methods has become increasingly challenging in recent years [6]. All these requirements deeply impact the choice of sample preparation techniques and instrumental methodologies.

The focus of separation methods in biomedical analysis includes not only medicine studies but also their use for illicit purposes [7], in forensic investigations [8], or with environmental concerns [9]. These areas, given only as examples, range from the academic discovery of novel entities to the development of new active pharmaceutical ingredients and therapeutics to the assessment of safety and efficacy. The suitability of the analytical methodology is generally based on factors such as the physicochemical properties of the analyte, the expected concentration, the origin (plant, animal, etc.) and the nature of the sample (solid, liquid, etc.) as well as the quantity of expected samples.

In the family of separative methods, gas chromatography hyphenated with mass spectrometry is one of the assets to detect and quantify small volatile molecules. It is commonly used in toxicological studies to evaluate cytotoxicity [10], in food monitoring to evaluate cultivars and cooking characteristics of an ingredient [11,12], or in environmental investigation $[13,14]$. Liquid chromatography (LC), coupled or not with mass spectrometry, is another predilection tool to perform separations as it has been spread worldwide for decades now. When it comes to non-volatile molecules, LC is addressed as the gold standard for analyte separations and detections $[15,16]$.

It should also be kept in mind that biological samples often imply complex matrices with multiple analysis issues such as numerous interferences as well as extremely low concentration levels of some analytes of interest, whether endogenous or exogenous [17]. The intrinsic instability and ease of degradation of these matrices only add to the difficulty. In many cases, the problems can be solved directly with suitable sample processing and various solutions have been developed in recent years. From the classical liquid/solid or liquid/liquid extractions [18,19], new or innovative pretreatment methods are now emerging.

One of the current directions is miniaturization, which today leads from solid-phase extraction (SPE) to solid-phase microextraction (SPME). Recently, SPME has been used to track down pollutants or chemicals in food or cosmetics [18]. An interesting proposal is the 
nanostructuration of extraction supports. These devices allow for very specific extractions, for instance, thiol analysis using gold nanoparticles [19], drug extraction using silver nanoparticles [20], or the extraction of heavy metals using quantum dots [21]; other types of nanoparticles are also being studied [22]. Miniaturization and the use of nanomaterials allow to increase the extraction efficiency thanks to the higher specific surface of the support and thus to the surface available to interact with the targeted molecules. However, when it comes to detecting or quantifying nanoparticles in complex matrices, the task becomes really difficult (low concentrations and matrix effect), especially when the initial physicochemical characteristics of these nano-objects are poorly defined [23-27].

The few examples previously introduced demonstrate that the development of separation methods for biomedical analysis is still a booming field. To address and illustrate all the points previously mentioned, the Special Issue "Separations in biomedical analysis" was imagined and includes the following papers:

Alqahtani et al., in their paper, "GC-MS Method for Quantification and Pharmacokinetic Study of Four Volatile Compounds in Rat Plasma after Oral Administration of Commiphora myrrh (Nees) Engl. Resin and In Vitro Cytotoxic Evaluation", reported the development and validation of a GC-MS method to quantify curzerene, methoxyfuranodiene, $\beta$-elemene, and $\alpha$-pinene in rat plasma. The method was validated according to FDA recommendations and attained lower limits of quantification around $4 \mathrm{ng} / \mathrm{mL}$ for volatile compounds. That led the authors to evaluate pharmacokinetics of these four compounds in vivo and their antiproliferative activity against two cell lines (carcinoma (A549) and colon (LoVo) cell lines). They found that methoxifuranodiene presented the higher antiproliferative activity against both cell lines, with an EC50 around $25 \mu \mathrm{M}$ [10].

Chaigneau et al., in the manuscript, "Monitoring of Gold Biodistribution from Nanoparticles Using a HPLC-Visible Method", described the development of a pretreatment method to further quantify gold from nanoparticles with HPLC coupled to a visible detection. The small gold nanoparticle size $(<10 \mathrm{~nm})$ can lead to the crossing of biological membranes and possibly implies problematic dissemination and storage in organs that must be controlled and evaluated. In this work, a simple isocratic HPLC method was developed and validated to quantify gold originated from nanoparticles degradation in different biological samples. After a first carbonization step at $900^{\circ} \mathrm{C}$, the nanoparticles were oxidized using dibroma under acidic conditions, leading to tetrachloroaurate ions that could form ion pairs with rhodamine B. Finally, ion pairs were extracted and the rhodamine B content was evaluated to quantify the corresponding gold concentration by reversed-phase HPLC with visible detection. The method was validated for different organs (liver, spleen, lungs, kidneys, or brain) and fluids (plasma and urine) from rats and mice. Lastly, the developed method was used to evaluate the content of gold in organs and fluids after intravenous (IV) injection of nanoparticles [27].

The third article, written by Sharma et al., discussed "Designing Safer Solvents to Replace Methylene Chloride for Liquid Chromatography Applications Using Thin-Layer Chromatography as a Screening Tool". They intended to develop new solvents for separative techniques to reduce their harmfulness. Methylene chloride, commonly known as dichloromethane (DCM), is a widely used chemical for chromatography separation within the polymer, chemical, and pharmaceutical industries. With the ability to effectively solvate heterocyclic compounds, and properties including a low boiling point, high density, and low cost, DCM has become the solvent of choice for many different applications. However, DCM has high neurotoxicity and is carcinogenic, with exposure linked to damage to the brain and the central nervous system, even at low exposure levels. This research focuses on sustainability and works towards finding safer alternative solvents to replace DCM in pharmaceutical manufacturing. The research was conducted with three active pharmaceutical ingredients (API) widely used in the pharmaceutical industry: acetaminophen, aspirin, and ibuprofen. Thin-layer chromatography (TLC) was used to investigate if an alternative solvent or solvent blend could show comparable separation performance to DCM. The use of the Hansen solubility parameter (HSP) theory and solubility testing 
allowed for the identification of potential alternative solvents or solvent blends to replace DCM. The HSP values for the three APIs were experimentally determined and used to identify safer solvents and blends that could potentially replace DCM. Safer solvents or binary solvent blends were down-selected based on their dissolution power, safety, and price. The down-selected solvents (e.g., ethyl acetate) and solvent blends were further evaluated using three chemical hazard classification approaches to find the best fitting nonhazardous replacement to DCM. Several safer solvent blends (e.g., mixtures composed of methyl acetate and ethyl acetate) with adequate TLC performance were identified. The results from this study are expected to provide guidance for identifying and evaluating safer solvents to separate APIs using chromatography [28].

When it comes to sensible separations, El-Behairy et al. displayed their work concerning "Enantioselective Chromatographic Separation and Lipase Catalyzed Asymmetric Resolution of Biologically Important Chiral Amines". They showed the importance of the separation of several chiral amines. Cyanoacetamides are vital synthons in synthetic organic chemistry. However, methods to enantiopure cyanoacetamides have not yet been well explored. In this work, the preparation of cyanoacetamide synthons RS-(1a-4a) or methoxyacetamides RS- $(1 b-4 b)$ in enantiopure/enriched form was investigated. Compounds S-1, $\mathrm{S}-2, \mathrm{R}-1 \mathrm{~b}, \mathrm{R}-1 \mathrm{a}$, andR-2b were prepared in enantiopure form (enantiomeric excess ee $>99 \%$ ) while compounds S-4, R-2a, and R-4a were achieved in ee $9 \%, 80 \%$, and $76 \%$, respectively. Many baseline enantioselective HPLC separations of amines 1-4, their cyanoacetamides $(1 \mathrm{a}-4 \mathrm{a})$, and methoxyacetamides $(1 \mathrm{~b}-4 \mathrm{~b})$ were achieved by utilizing diverse mobile-phase compositions and two cellulose-based CSPs (ODH ${ }^{\circledR}$ and LUX- $3^{\circledR}$ columns). Such enantioselective HPLC separations were used to monitor the lipase-catalyzed kinetic resolution of amines RS-(1-4) [29].

Finally, Kumagai et al. used an HPLC method to quantify peptides in their work entitled "Quantification of Histidine-Containing Dipeptides in Dolphin Serum Using a Reversed-Phase Ion-Pair High-Performance Liquid Chromatography Method". The quantification of histidine-containing dipeptides (anserine, carnosine, and balenine) in serum might be a diagnostic tool to assess the health condition of animals. In this study, an existing reversed-phase ion-pair high-performance liquid chromatography (HPLC)-ultraviolet detection method was improved and validated to quantify serum anserine, carnosine, and balenine levels in the dolphin. The serum was deproteinized with trichloroacetic acid and directly injected into the HPLC system. Chromatographic separation of the three histidinecontaining dipeptides was achieved on a TSK-gel ODS-80Ts $(4.6 \mathrm{~mm} \times 150 \mathrm{~mm}, 5 \mu \mathrm{m})$ analytical column using a mobile phase of $50 \mathrm{mmol} / \mathrm{L}$ potassium dihydrogen phosphate (pH 3.4) containing $6 \mathrm{mmol} / \mathrm{L}$ 1-heptanesulfonic acid and acetonitrile (96:4). The standard curve ranged from $0.1 \mu \mathrm{mol} / \mathrm{L}$ to $250 \mu \mathrm{mol} / \mathrm{L}$. The average accuracy of the intra- and inter-analysis of anserine, carnosine, and balenine was $97-106 \%$. The relative standard deviations of total precision (RSDr) of anserine, carnosine, and balenine in dolphin serum were $5.9 \%, 4.1 \%$, and $2.6 \%$, respectively. The lower limit of quantification of these compounds was $0.11-0.21 \mu \mathrm{mol} / \mathrm{L}$. These results indicate that the improved method is reliable and concise for the simultaneous determination of anserine, carnosine, and balenine in dolphin serum, and may be useful for the evaluation of health conditions in dolphins. Furthermore, this method can also be applied to other biological samples [17].

Author Contributions: Conceptualization, I.C.; writing—original draft preparation, A.P. and I.C.; writing-review and editing, A.P., A.B., J.G., and I.C. All authors have read and agreed to the published version of the manuscript.

Funding: This research received no external funding.

Institutional Review Board Statement: Not applicable.

Informed Consent Statement: Not applicable.

Data Availability Statement: Not applicable.

Conflicts of Interest: The authors declare no conflict of interest. 


\section{References}

1. Kim, T.H.; Thapa, S.K.; Lee, D.Y.; Chung, S.E.; Lim, J.Y.; Jeong, H.M.; Song, C.H.; Choi, Y.-W.; Cho, S.-M.; Nam, K.-Y.; et al. Pharmacokinetics and Anti-Gastric Ulceration Activity of Oral Administration of Aceclofenac and Esomeprazole in Rats. Pharmaceutics 2018, 10, 152. [CrossRef] [PubMed]

2. Desrosiers, M.; Pelletier, G.; Dieme, D.; Côté, J.; Jomaa, M.; Nong, A.; Bouchard, M. Toxicokinetics in Rats and Modeling to Support the Interpretation of Biomonitoring Data for Rare-Earth Elements. Environ. Int. 2021, 155, 106685. [CrossRef] [PubMed]

3. Rao, G.G.; Landersdorfer, C.B. Antibiotic Pharmacokinetic/Pharmacodynamic Modelling: MIC, Pharmacodynamic Indices and Beyond. Int. J. Antimicrob. Agents 2021, 58, 106368. [CrossRef] [PubMed]

4. Luke, M.C.; Kozak, D. Regulating Generic Ophthalmologic Drug Bioequivalence-Envisioning Accessibility for Patients. J. Ocul. Pharmacol. Ther. 2021, 37, 157-161. [CrossRef] [PubMed]

5. Christians, U.; Klawitter, J.; Clavijo, C.F. Bioequivalence Testing of Immunosuppressants: Concepts and Misconceptions. Kidney Int. 2010, 77, S1-S7. [CrossRef]

6. Moein, M.M.; El Beqqali, A.; Abdel-Rehim, M. Bioanalytical Method Development and Validation: Critical Concepts and Strategies. J. Chromatogr. B 2017, 1043, 3-11. [CrossRef]

7. Van Echelpoel, R.; de Jong, M.; Daems, D.; Van Espen, P.; De Wael, K. Unlocking the Full Potential of Voltammetric Data Analysis: A Novel Peak Recognition Approach for (Bio)Analytical Applications. Talanta 2021, 233, 122605. [CrossRef]

8. Sofalvi, S.; Schueler, H.E. Assessment of Bioanalytical Method Validation Data Utilizing Heteroscedastic Seven-Point Linear Calibration Curves by EZSTATSG1 Customized Microsoft Excel Template. J. Anal. Toxicol. 2021, 45, 772-779. [CrossRef]

9. Sobiech, M.; Luliński, P.; Wieczorek, P.P.; Marć, M. Quantum and Carbon Dots Conjugated Molecularly Imprinted Polymers as Advanced Nanomaterials for Selective Recognition of Analytes in Environmental, Food and Biomedical Applications. TrAC Trends Anal. Chem. 2021, 142, 116306. [CrossRef]

10. Alqahtani, A.S.; Herqash, R.N.; Alqahtani, F.; Ahamad, S.R.; Nasr, F.A.; Noman, O.M. GC-MS Method for Quantification and Pharmacokinetic Study of Four Volatile Compounds in Rat Plasma after Oral Administration of Commiphora Myrrh (Nees) Engl. Resin and In Vitro Cytotoxic Evaluation. Separations 2021, 8, 239. [CrossRef]

11. Fan, X.; Jiao, X.; Liu, J.; Jia, M.; Blanchard, C.; Zhou, Z. Characterizing the Volatile Compounds of Different Sorghum Culti-vars by Both GC-MS and HS-GC-IMS. Food Res. Int. 2021, 140, 109975. [CrossRef] [PubMed]

12. Kaltbach, P.; Gillmeister, M.; Kabrodt, K.; Schellenberg, I. Screening of Volatile Compounds in Mate (Ilex Paraguariensis) Tea-Brazilian Chimarrão Type-By HS-SPDE and Hydrodistillation Coupled to GC-MS. Separations 2021, 8, 131. [CrossRef]

13. Rashid, A.; Ali, V.; Khajuria, M.; Faiz, S.; Gairola, S.; Vyas, D. GC-MS Based Metabolomic Approach to Understand Nutraceutical Potential of Cannabis Seeds from Two Different Environments. Food Chem. 2021, 339, 128076. [CrossRef] [PubMed]

14. Ishimura, T.; Iwai, I.; Matsui, K.; Mattonai, M.; Watanabe, A.; Robberson, W.; Cook, A.-M.; Allen, H.L.; Pipkin, W.; Teramae, N.; et al. Qualitative and Quantitative Analysis of Mixtures of Microplastics in the Presence of Calcium Carbonate by Pyroly-sisGC/MS. J. Anal. Appl. Pyrolysis 2021, 157, 105188. [CrossRef]

15. Steiner, D.; Malachová, A.; Sulyok, M.; Krska, R. Challenges and Future Directions in LC-MS-Based Multiclass Method Development for the Quantification of Food Contaminants. Anal. Bioanal. Chem. 2021, 413, 25-34. [CrossRef] [PubMed]

16. Arvapally, M.; Asati, A.; Nagendla, N.K.; Mudiam, M.K.R. Development of an Analytical Method for the Quantitative Determination of Multi-Class Nutrients in Different Food Matrices by Solid-Phase Extraction and Liquid Chromatog-raphy-Tandem Mass Spectrometry Using Design of Experiments. Food Chem. 2021, 341, 128173. [CrossRef] [PubMed]

17. Kumagai, M.; Kato, S.; Arakawa, N.; Otsuka, M.; Hamano, T.; Kashiwagi, N.; Yabuki, A.; Yamato, O. Quantification of His-tidineContaining Dipeptides in Dolphin Serum Using a Reversed-Phase Ion-Pair High-Performance Liquid Chromatography Method. Separations 2021, 8, 128. [CrossRef]

18. Feng, J.; Feng, J.; Ji, X.; Li, C.; Han, S.; Sun, H.; Sun, M. Recent Advances of Covalent Organic Frameworks for Solid-Phase Microextraction. TrAC Trends Anal. Chem. 2021, 137, 116208. [CrossRef]

19. Wang, M.; Chen, Z.; Jing, X.; Zhou, H.; Wang, Y.; Ye, J.; Chu, Q. Tween 20-Capped Gold Nanoparticles for Selective Extrac-tion of Free Low-Molecular-Weight Thiols in Saliva Followed by Capillary Electrophoresis with Contactless Conductivity Detection. J. Chromatogr. B 2021, 1176, 122756. [CrossRef]

20. Sahebnasagh, S.; Fadaee Kakhki, J.; Ebrahimi, M.; Bozorgmehr, M.R.; Abedi, M.R. Pre-Concentration and Determination of Fluoxetine in Hospital Wastewater and Human Hair Samples Using Solid-Phase $\mu$-Extraction by Silver Nanoparticles Fol-lowed by Spectro-Fluorimetric. Chem. Methodol. 2021, 5, 211-218. [CrossRef]

21. Chen, M.; Liu, T.; Zhang, X.; Zhang, R.; Tang, S.; Yuan, Y.; Xie, Z.; Liu, Y.; Wang, H.; Fedorovich, K.V.; et al. Photoinduced Enhancement of Uranium Extraction from Seawater by MOF/Black Phosphorus Quantum Dots Heterojunction Anchored on Cellulose Nanofiber Aerogel. Adv. Funct. Mater. 2021, 31, 2100106. [CrossRef]

22. Chiarello, M.; Anfossi, L.; Cavalera, S.; Di Nardo, F.; Serra, T.; Baggiani, C. NanoMIP-Based Solid Phase Extraction of Fluoroquinolones from Human Urine: A Proof-of-Concept Study. Separations 2021, 8, 226. [CrossRef]

23. Pallotta, A.; Boudier, A.; Creusot, B.; Brun, E.; Sicard-Roselli, C.; Bazzi, R.; Roux, S.; Clarot, I. Quality Control of Gold Nanoparticles as Pharmaceutical Ingredients. Int. J. Pharm. 2019, 569, 118583. [CrossRef] [PubMed]

24. Mayhew, T.M.; Mühlfeld, C.; Vanhecke, D.; Ochs, M. A Review of Recent Methods for Efficiently Quantifying Immunogold and Other Nanoparticles Using TEM Sections through Cells, Tissues and Organs. Ann. Anat.-Anat. Anz. 2009, 191, 153-170. [CrossRef] 
25. Bocca, B.; Caimi, S.; Senofonte, O.; Alimonti, A.; Petrucci, F. ICP-MS Based Methods to Characterize Nanoparticles of TiO2 and $\mathrm{ZnO}$ in Sunscreens with Focus on Regulatory and Safety Issues. Sci. Total Environ. 2018, 630, 922-930. [CrossRef]

26. Pallotta, A.; Clarot, I.; Sobocinski, J.; Fattal, E.; Boudier, A. Nanotechnologies for Medical Devices: Potentialities and Risks. ACS Appl. Bio Mater. 2019, 2, 1-13. [CrossRef]

27. Chaigneau, T.; Pallotta, A.; Benaddi, F.Z.; Sancey, L.; Chakir, S.; Boudier, A.; Clarot, I. Monitoring of Gold Biodistribution from Nanoparticles Using a HPLC-Visible Method. Separations 2021, 8, 215. [CrossRef]

28. Sharma, A.; Yu, E.; Morose, G.; Nguyen, D.T.; Chen, W.-T. Designing Safer Solvents to Replace Methylene Chloride for Liq-uid Chromatography Applications Using Thin-Layer Chromatography as a Screening Tool. Separations 2021, 8, 172. [CrossRef]

29. El-Behairy, M.F.; Hassan, R.M.; Sundby, E. Enantioselective Chromatographic Separation and Lipase Catalyzed Asymmetric Resolution of Biologically Important Chiral Amines. Separations 2021, 8, 165. [CrossRef] 